\title{
The Effect of Exercise Methods and Emotional Intelligence on Students' Dribbling Capabilities who are Football Extracurricular Participants at all State Junior High Schools in Pekalongan City Indonesia
}

\author{
Hendra Kurniawan ${ }^{1 *}$, Prof. DR. FX. Sugiyanto, M. Pd ${ }^{2}$ \\ ${ }^{1}$ Sport Science Study Program, Postgraduate Program, Yogyakarta State University. Jalan Colombo No. 1, \\ Karangmalang, Yogyakarta, Indonesia.13711251038@student.uny.ac.id; gerbil_74@yahoo.com \\ ${ }^{2}$ Lecturer of UNY Graduate Program, Yogyakarta State University. Jalan Colombo No. 1, Karangmalang, \\ Yogyakarta, Indonesia
}

*Corresponding Author: Hendra Kurniawan, Sport Science Study Program, Postgraduate Program, Yogyakarta State University. Jalan Colombo No. 1, Karangmalang, Yogyakarta, Indonesia

\begin{abstract}
The purpose of this research is to know the difference of effect and interaction between the training method and emotional intelligence level towards the ability improvement of football dribbling. This research was experimental research by using factorial design $2 X 2$. This research had been conducted at State Junior High School, Pekalongan City for two months started from March until April 2019 with total samples of 75 students. The research hypothesis test was conducted by using two way ANOVA started with a prerequisite test using a normality test and homogeneity test. To know the main effect (interaction) used Tukey test. This research concludes that there is the difference and the interaction occurs between the training method (reciprocal and discovery) and emotional intelligence towards dribbling ability improvement of athlete the participants of football extracurricular at State Junior High School within Pekalongan. Until it is suggested to the coach to use the reciprocal method in improving dribbling ability of athlete with high emotional intelligence and use discovery training method to enhance dribbling ability of athlete with low emotional intelligence.
\end{abstract}

Keywords: The training method, emotional intelligence, dribbling ability

\section{INTRODUCTION}

Football is one of the exciting and fun sports. The facilities and infrastructure that are easily available make football popular and favoured by all people in Indonesia[1]. In addition, football sports coaching in corporate agencies, government and educational institutions is also growing. As a result of the inclusion of physical education in the education curriculum and efforts to popularise sports among the community, causing various forms of sports training models which are also developing. In the formal education environment, for example, activities that lead to the development of sports skills through extracurricular activities with the application of several styles/methods of the training start to be varied as an effort to increase the ability to be more maximal.

The results of the training process will be maximal if the method used is by the conditions faced[2]. Many schools and club levels, especially in the regions, as well as in Pekalongan State Junior High School still do not apply varied training methods that are adjusted from the results of previous evaluations. The pattern of football training in extracurricular activities at all State Junior High Schools in Pekalongan has only used conventional drill exercises with limited infrastructure and trainers. During training, an athlete is only given a ball and inadequate training without maximum observation from the trainer due to insufficient energy, so the athlete cannot immediately correct errors. As a result, in subsequent exercises, the athlete still made the same mistake because there was no structured evaluation of the activities that had been done before.

Based on the problems and conditions that have existed in the Pekalongan City, especially at the State Junior High School level, several training models such as reciprocal and discovery style exercises can 
be used in football practice in schools through extracurricular activities. Reciprocal exercise and discovery are training models that encourage athletes to work together in the tasks of certain groups, forms of group work, or in additional group training activities[3]. The method of training has an impact on the athlete and the conditions needed to create effective training $[4,5]$.

At the age of growth, children receive a new thing more quickly, especially in terms of movement if they are given directed and regularly[6]. However, it is not easy for children to be able to move or play football well. A process is needed so that the child's movement skills in playing football can be mastered well. This is because football is a game that demands speed, flexibility and agility for every football player.

The level of emotional intelligence of a football athlete, of course, will greatly affect the maturity and calmness of playing in a match[7]. With good emotional intelligence, it is expected that a football athlete will be able to master the game because he has a good mentality, in addition to mature techniques[8].

The football extracurricular training activities at State Junior High School in Pekalongan City have been going well nowadays. It's just that the effectiveness and results obtained are not too satisfying. There are still many athletes who have not been able to do well the basic techniques that are given, for example in dribbling techniques. Dribbling is very important to be mastered by every player because all players must be able to master the ball when moving, standing, or ready to make shots or passes. Dribbling is not always done by every football player but can be useful when a player is in a tight situation. Dribbling done by a player can be used to break away from opponents, look for space, can even be used to break through enemy defences and then shoot or feed to friends. Therefore, dribbling is one of the hardest techniques for all football athletes to master well.

On the other hand, the average level of emotional intelligence of the athletes of the State Junior High Schools in Pekalongan City has not shown the expected results. There are still many deviant behaviours, juvenile delinquency, and attitudes that show a low level of emotional intelligence.

Based on the problemsabove, this study examined the effect of reciprocal and discovery training methods and the level of emotional intelligence on improving the capability of football techniques that are focused on dribbling on football extracurricular.

\section{RESEARCH METHODOLOGY}

\subsection{Research Design}

This research is experimental research. The research method used in this study was by using a $2 \times 2$ factorial design. Based on the number of variables available, these are: (1) active/independent variables namely training methods (reciprocal and discovery), (2) passive/moderator variable, namely high and low emotional intelligence.Fourteen meetings were carried out as the treatments, where there are four meetings in a week with a duration of 90 minutes per meeting.

\subsection{Research Population and Samples}

The population of this study were all athletes of extracurricular football participants in all State Junior High Schools in Pekalongan city. There was total of eight schoolsas the population consists of 240 athletes. The samples used were two schools which weretaken randomly by usinga random sampling system. In this study, the author took 75 children as samples according to the number of athletes who are participants in football extracurricular activities at the two schools.

Before the experiment was carried out, the 75 athletes as samples were tested with an instrument of emotional intelligence developed from Jeane's theory, that is about the scope of EQ [9], namely personal and social intelligence. This test is used to determine the initial score which shows the level of emotional intelligence (EQ).

After the EQ test data is collected, the first step in the analysis is to identify the upper and lower groups using the overall test score. In the analysis, it was used $27 \%$ of the score, both for the upper and lower groups. 
The Effect of Exercise Methods and Emotional Intelligence on Students' Dribbling Capabilities who are Football Extracurricular Participants at all State Junior High Schools in Pekalongan City Indonesia

\subsection{Data Analysis Technique}

Once collected, the next step is to analyse the data. In this study, statistical analysis was used to analysis the data. There are three stages of the test that were carried out, namely the prerequisite testing (Normality Test and Homogeneity Test), hypothesis testing (two-way ANOVA) and further testing (Post Hoc Test).

\section{RESULTS AND DISCUSSION}

\subsection{Description of Research Data}

Descriptive statistics of pre-test and post-test results of football dribbling capability of athletes who are participants in extracurricular activities at all Junior High Schools in Pekalongan City are presented in table 1 below.

Table1: Descriptive Statistics of Pretest and Posttest dribbling capabilities

\begin{tabular}{|c|c|c|c|c|c|c|}
\hline \multicolumn{7}{|c|}{ High Emotional Intelligence } \\
\hline & \multicolumn{3}{|c|}{ Reciprocal (A1B1) } & \multicolumn{3}{|c|}{ Discovery (A1B2) } \\
\hline & Pretest & Posttest & Gain & Pretest & Posttest & Gain \\
\hline Total & 285.11 & 224.90 & 60.21 & 280.90 & 241.85 & 39.05 \\
\hline Average & 28.51 & 22.49 & 6.02 & 28.09 & 24.19 & 3.91 \\
\hline \multicolumn{7}{|c|}{ Low Emotional Intelligence } \\
\hline & \multicolumn{3}{|c|}{ Resiprocal (A2B1) } & \multicolumn{3}{|c|}{ Discovery (A2B2) } \\
\hline & Pretest & Posttest & Gain & Pretest & Posttest & Gain \\
\hline Total & 282.85 & 259.90 & 22.95 & 289.85 & 233.90 & 55.95 \\
\hline Average & 28.29 & 25.99 & 2.30 & 28.99 & 23.39 & 5.60 \\
\hline
\end{tabular}

Based on the data in table 1, it can be seen that the highest increase was in the use of reciprocal exercise models in the high emotional intelligence group which was equal to 6.02. The next highest increase was found in the use of the discovery training method in the low emotional intelligence group that is5.60. The use of the discovery exercise method in the high emotional intelligence group was only able to produce an increase in difference of 3.91, and the use of the reciprocal method in the low emotional intelligence group was only able to increase by 2.30 .

If it is presented in the form of a diagram, the results of pretest and posttest data of the athletes' football dribbling capability who are participants in football extracurricular at all Junior High Schools in Pekalongan City are presented in figure 1 below.

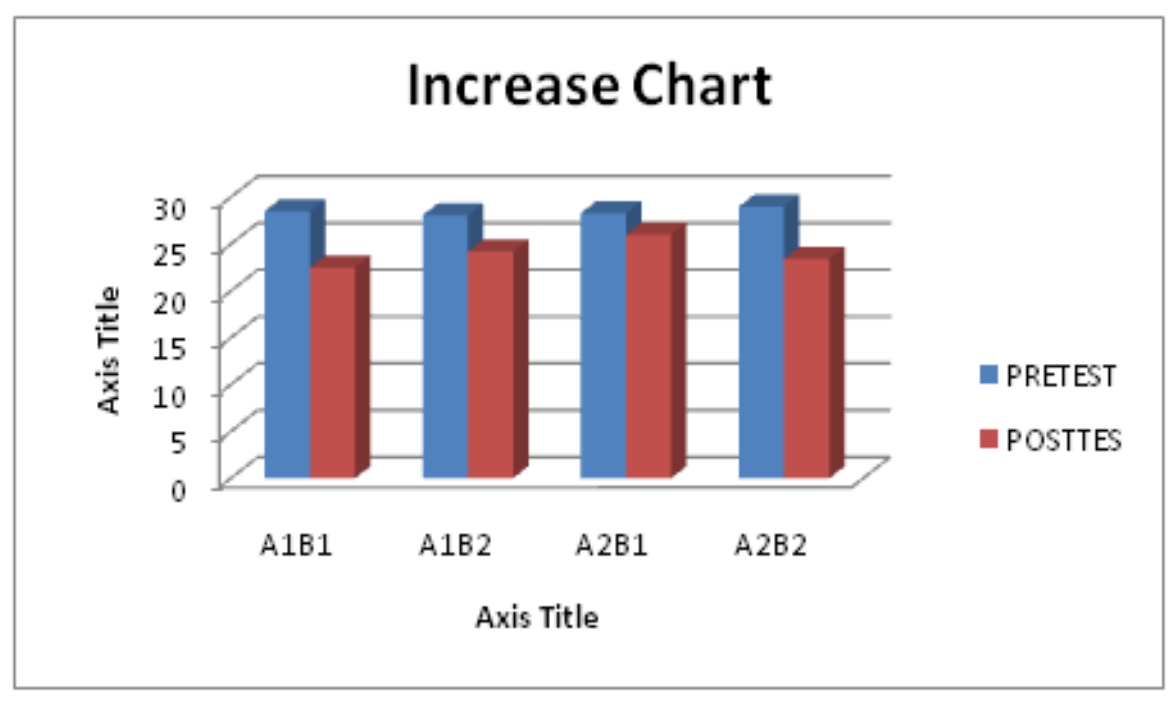

Figure1: Bar Diagram of Pre Test and Post-test Dribbling Capability

\subsection{Prerequisite Test Results}

\subsubsection{Normality Test}

Kolmogorov Smirnov method was used to do a normality test of the data in this study. The results of the data normality test performed on each analysis group were carried out by using the SPSS version 
The Effect of Exercise Methods and Emotional Intelligence on Students' Dribbling Capabilities who are Football Extracurricular Participants at all State Junior High Schools in Pekalongan City Indonesia

16.0 for Windows software with a significance level of $5 \%$ or $0.05[10,11]$. The full results are presented in table 2 as follows.

Table2: Normality Test

\begin{tabular}{|c|c|c|c|}
\hline Data & $\boldsymbol{P}$ & Significance & Description \\
\hline Pretest A1B1 & 0.061 & \multirow{8}{*}{0,05} & Normal \\
\hline Posttest A1B1 & 0.798 & & Normal \\
\hline Pretest A1B2 & 0.182 & & Normal \\
\hline Posttest A1B2 & 0.196 & & Normal \\
\hline Pretest A2B1 & 0.069 & & Normal \\
\hline Posttest A2B1 & 0.321 & & Normal \\
\hline Pretest A2B2 & 0.476 & & Normal \\
\hline Posttest A2B2 & 0.350 & & Normal \\
\hline
\end{tabular}

Based on the statistical analysis of normality test that has been carried out using the Z Kolmogorov Smirnov test, on all pretest and posttest data of athletes' football dribbling ability who are participants in football extracurricular at all Junior High Schools in Pekalongan City, it was found that the significance value was $\mathrm{p}>0.05$, which means the data are normally distributed.

\subsubsection{Homogeneity Test}

Homogeneity test is carried out to test the equations of several samples which are homogeneous or not. The homogeneity test is intended to test the similarity of variants between pretest and posttest. The homogeneity test in this study was the Levene Test[10, 11]. The homogeneity test results are presented in table 3 below.

Table3: Results of Homogeneity Test

\begin{tabular}{|l|l|l|l|l|l|}
\hline \multicolumn{1}{|c|}{ Group } & \multicolumn{1}{c|}{ Levene Statistic } & \multicolumn{1}{c|}{ df1 } & df2 & \multicolumn{1}{c|}{ Sig. } & \multicolumn{1}{c|}{ Description } \\
\hline Pretest & 0.613 & 1 & 38 & 0.439 & Homogeneous \\
\hline Posttest & 0.064 & 1 & 38 & 0.802 & Homogeneous \\
\hline
\end{tabular}

Based on the statistical analysis of homogeneity test that has been carried out using the Levene Test test, in the pretest, a significance value of $0.439 \geq 0.05$ was obtained. This means that in the pretest data group had a homogeneous variant. While the results of calculations on posttest have a significance value of $0.802 \geq 0.05$ which means that in the group data of posttest, it has a homogeneous variant. Thus the population has the same variance or homogeneity.

\subsection{Hypothesis Test Results}

The hypothesis testing in this research was carried out based on the results of data analysis and interpretation of two-way ANOVA analysis (two-way ANOVA). The results of the analysis and presentation are as follows.

Based on the results of the analysis, the data obtained are shown in table 4.

Table4: The results of two-way ANOVA analysis

\begin{tabular}{|l|l|l|l|l|l|}
\hline \multicolumn{1}{|c|}{ Source } & \multicolumn{1}{c|}{ Type III Sum of Squares } & \multicolumn{1}{c|}{ df } & \multicolumn{1}{c|}{ Mean Square } & \multicolumn{1}{c|}{ F } & Sig. \\
\hline K_Emotion & 10.363 & 1 & 10.363 & 9.161 & .005 \\
\hline Method & 3.505 & 1 & 3.505 & 3.098 & .087 \\
\hline K_Emotion * Method & 73.333 & 1 & 73.333 & 64.822 & .000 \\
\hline
\end{tabular}

From the results of ANOVA test in table 4 above, it can be seen that Fcount $=3.098$, while the significance value of $\mathrm{p}$ is 0.087 or $\mathrm{p}$ is $0.087>0.05$, which means that Ho is accepted. Thus there is no significant difference in the reciprocal training and discovery method on the increase of football athletes' dribbling capability who are participants in football extracurricular at all Junior High Schools in Pekalongan City.Nevertheless, based on the analysis results of the difference in the value of the pretest and post-test, it turns out that the discovery training method is higher with the average value of difference between pretest and posttest was 4.75 compared to the reciprocal training method with an average value of difference between pretest and posttest that was 4.16. These results are presented in the picture below. 
The Effect of Exercise Methods and Emotional Intelligence on Students' Dribbling Capabilities who are Football Extracurricular Participants at all State Junior High Schools in Pekalongan City Indonesia

From the results of the ANOVA test in table 4 above, it can be seen that Fcount $=9,161$, while the significance value is 0.005 or $\mathrm{p}$ is $0.005<0.05$, which means that Ho is rejected. Based on this, it means that there is a significant difference in influence between high emotional intelligence and low emotional intelligence on the increase of dribbling capability of athletes who are participants in football extracurricular at all Junior High Schools in Pekalongan City. The results are presented in the figure below.

From the ANOVA test results in table 4 above, it can be seen that Fcount $=64.822$, while the significance value of $p$ is 0.000 or $p$ is $0,000<0,05$ which means that Ho is rejected. Based on this, it means that the hypothesis which states that there is an interaction between training methods (reciprocal and discovery) and emotional intelligence to increase on dribbling capability of athletes who are participants in football extracurricular at all Junior High School in Pekalongan City has been proven.

\subsection{Post Hoc Test}

After being tested and found that there were interactions between training methods (reciprocal and discovery) and emotional intelligence (high and low) on the dribbling capability of the athletes who are participants in football extracurricular at all Junior High Schools in Pekalongan City, then further testing was needed. The Tukey test was used in this further testing. Further results can be seen in table 5 below:

Table5: Summary of Post Hoc Test Results

\begin{tabular}{|l|l|l|l|l|l|}
\hline Group & Interaction & Sig. & Mean Difference & Std. Error Difference & \multicolumn{1}{|c|}{ Description } \\
\hline \multirow{4}{*}{ A1BI } & A1B2 & 0.001 & 2.11600 & 0.54181 & Significant \\
\cline { 2 - 6 } & A2B1 & 0.000 & 3.72600 & 0.50376 & Significant \\
\cline { 2 - 6 } & A2B2 & 0.431 & 0.42600 & 0.52925 & Not Significant \\
\hline \multirow{5}{*}{ A1B2 } & A1B1 & 0.001 & -2.11600 & 0.54181 & Significant \\
\cline { 2 - 6 } & A2B1 & 0.001 & 1.61000 & 0.41522 & Significant \\
\cline { 2 - 6 } & A2B2 & 0.001 & -1.69000 & 0.44580 & Significant \\
\hline A2B1 & A1B1 & 0.000 & -3.72600 & 0.50376 & Significant \\
\cline { 2 - 6 } & A1B2 & 0.001 & -1.61000 & 0.41522 & Significant \\
\cline { 2 - 6 } & A2B2 & 0.000 & -3.30000 & 0.39870 & Significant \\
\hline \multirow{3}{*}{ A2B2 } & A1B1 & 0.431 & -0.42600 & 0.52925 & Signifikan \\
\cline { 2 - 6 } & A1B2 & 0.001 & 1.69000 & 0.44580 & Signifikan \\
\cline { 2 - 6 } & A2B1 & 0.000 & 3.30000 & 0.39870 & \\
\hline
\end{tabular}

Information:

A1B1: The football dribbling capability of athletes who have high emotional intelligence given the reciprocal method.

A1B2: The football dribbling capability of athletes who have high emotional intelligence given the Discovery method.

A2B1: The football dribbling capability of athletes who have low emotional intelligence given the reciprocal method.

A2B2: The football dribbling capability of athletes who have low emotional intelligence given the Discovery method.

The conclusions from the posthoc test results in table 5 are as follows:

- If athletes who have high emotional intelligence are given reciprocal methods (A1B1) compared to athletes who have high emotional intelligence given the Discovery method (A1B2), then the results of the analysis show that there are significant differences in the effect, with a significance value of $0.001<0.005$. Based on the difference value data shows the average value of the difference between athletes who have high emotional intelligence given the reciprocal method is 6.02, while the athletes who have high emotional intelligence given the Discovery method is only 3.91. Therefore it can be concluded that the reciprocal method is more suitable to use for athletes who have high emotional intelligence than to use the discovery methods.

- If athletes who have high emotional intelligence given the reciprocal method (A1B1) compared to athletes who have low emotional intelligence given reciprocal methods (A2B1), then the results of 
the analysis show that there are significant differences in the effect, with a significance value of $0.000<0.005$. Based on the difference value data, it shows that the average value of the difference between athletes who have high emotional intelligence given the reciprocal method is 6.02 , while the athletes who have low emotional intelligence given the reciprocal method is only 2.30 . So it can be concluded that the reciprocal method is more suitable for athletes who have high emotional intelligence compared to athletes who have low emotional intelligence.

- If athletes who have high emotional intelligence are given a reciprocal method (A1B1) compared to athletes who have low emotional intelligence given the Discovery method (A2B2), then the results of the analysis show that there is no significant difference in effect, with a significance value of $0.431>0.005$. Based on the difference value data, it shows that the average score of the athletes who have high emotional intelligence given the reciprocal method is 6.02 , while the athletes who have low emotional intelligence given the Discovery method is only 5.60. Therefore it can be concluded that the reciprocal method is more suitable for athletes who have high emotional intelligence while the Discovery method is more suitable for athletes who have low emotional intelligence.

- If athletes who have high emotional intelligence are given the Discovery method (A1B2) compared to athletes who have low emotional intelligence given the reciprocal method (A2B1), then the results of the analysis show that there are significant differences in the effect, with a significance value of $0.001>0.005$. Based on the difference value data, it shows that the average value of the analysis of athletes who have high emotional intelligence given the Discovery method is 3.91, while athletes who have low emotional intelligence given reciprocal methods is only at 2.30 .

- If athletes who have high emotional intelligence are given the Discovery method (A1B2) compared to athletes who have low emotional intelligence given the Discovery method (A2B2), then the results of the analysis show that there are significant differences in the effect, with a significance value of $0.001>0.005$. Based on the value of the difference data, it shows that the average value of the analysis of athletes who have high emotional intelligence given the Discovery method is 3.91 , while athletes who have low emotional intelligence given reciprocal methods is 5.60 .

- If athletes who have low emotional intelligence are given reciprocal methods (A2B1) compared to athletes who have low emotional intelligence given the Discovery method (A2B2), then the results of the analysis show there are significant differences in the effect, with a significance value of $0,000<0,005$. Based on the value of the difference data, it shows that the average value of the analysis of athletes who have low emotional intelligence given reciprocal method is 2.30 , while athletes who have low emotional intelligence given the Discovery method is 5.60. Therefore it can be concluded that the discovery method is more suitable to use for athletes who have low emotional intelligence than to use the reciprocal method.

\section{CONCLUSION}

This research shows that reciprocal and discovery training method gives the results which are not significantly different in improving dribbling ability of athletes the participants of football extracurricular at State Junior High School within Pekalongan City. High and low emotional intelligence gives sufficiently significant difference towards the improvement of dribbling ability athlete the participants of football extracurricular in Junior High School within Pekalongan City. Besides that, the interaction occurs between the training method (reciprocal and discovery) and emotional intelligence towards the improvement of dribbling ability athlete the participants of football extracurricular at State Junior High School within Pekalongan.

Based on the research results, it is suggested to the coach to use Reciprocal training method to improve dribbling ability of athlete with high emotional intelligence and use discovery training method to improve dribbling ability of athlete with low emotional intelligence. For other researchers who would like to replicate this research, it is suggested to conduct tighter control in the overall experimental sequence. This control is conducted to avoid the threat of external and internal validity. 
The Effect of Exercise Methods and Emotional Intelligence on Students' Dribbling Capabilities who are Football Extracurricular Participants at all State Junior High Schools in Pekalongan City Indonesia

\section{REFERENCES}

[1] Saputra, H.: 'Model Pembelajaran Permainan Sepak Bola Gawang Bergerak Dalam Penjasorkes Pada Siswa Kelas Vii Smp Negeri 10 Semarang Tahun 2012/2013', Universitas Negeri Semarang, 2013

[2] Chan, F.: 'Strength Training (Latihan Kekuatan)', Cerdas Sifa Pendidikan, 2012, 1, (1)

[3] Spencer, L.M., and Spencer, P.S.M.: 'Competence at Work models for superior performance' (John Wiley \& Sons, 2008. 2008)

[4] Côté, J., and Gilbert, W.: 'An integrative definition of coaching effectiveness and expertise', International journal of sports science \& coaching, 2009, 4, (3), pp. 307-323

[5] Yaşar, A., and Gökhan, Ö.: 'Field: Sport Sciences, Sports Management Type', International Journal of Sport Culture and Science, 2016, 4, (2), pp. 177-186

[6] Knowles, M.S.: 'The modern practice of adult education', 1980

[7] Gucciardi, D.F., Gordon, S., and Dimmock, J.A.: 'Evaluation of a mental toughness training program for youth-aged Australian footballers: II. A qualitative analysis', Journal of Applied Sport Psychology, 2009, 21, (3), pp. 324-339

[8] ATEŞ, Ö.T.: 'A Different Perspective to Fine Art High School Students in Emotional Intelligence', International Journal of Science Culture and Sport, 2014, 2, (4), pp. 42-48

[9] Budi, E.N.: 'Hubungan antara kecerdasan emosional dan penguasaan struktur kalimat dengan kemampuan menulis eksposisi (survei di SMP Negeri kecamatan Jekulo kabupaten Kudus tahun 2008/2009)', Universitas Sebelas Maret, 2009

[10] Sugiyono: 'Metode penelitian pendidikan:(pendekatan kuantitatif, kualitatif dan R \& D)' (Alfabeta, 2008. 2008)

[11] Sugiyono: 'Statistika untuk penelitian', Bandung: CV. Alfabeta, 2006

Citation: Hendra Kurniawan, et.al. "The Effect of Exercise Methods and Emotional Intelligence on Students' Dribbling Capabilities who are Football Extracurricular Participants at all State Junior High Schools in Pekalongan City Indonesia" International Journal of Sports and Physical Education (IJSPE), vol 5, no. 2, 2019, pp. 30-36. doi: http://dx.doi.org/10.20431/2454-6380.0502004.

Copyright: (c) 2019 Authors. This is an open-access article distributed under the terms of the Creative Commons Attribution License, which permits unrestricted use, distribution, and reproduction in any medium, provided the original author and source are credited. 